\title{
Demographical and population dynamics impact on public health of cutaneous Leishmaniasis in Al-Madinah Almonawra, Saudi Arabia
}

\author{
Nazar M Abdalla ${ }^{1}$, Abdelgani M Abdelgani², Amani A Osman³, Mohamed N Mohamed ${ }^{4}$
}

1. Nazar M Abdalla, Ass. Prof., Consultant Medical Microbiologist. College of Medicine. King Khalid University. Abha, Saudi Arabia. E-mail: uofgnazar@gmail.com.

2. Abdelgani M Abdelgani, Microbiology Specialist. Faculty of Medical Lab. , Gezira University, Wad Medani, P.O.BOX 20, Sudan. E-mail : uofgnazarn@hotmail.com

3. Amani A Osman, Ass. Prof., Consultant Reproductive Health, Family \& Community Medicine Department. College of Medicine. King Khalid University. 61421 Abha, P.O. 641, Saudi Arabia.

Email: amanieldosh@gmil.com

4. Mohamed N Mohamed, Internist Abha General Hospital, 61421 Abha, P.O. 641, Saudi Arabia.

Email: bbe.dragon.mn@gmail.com

\begin{abstract}
:
Background: A cross-sectional study conducted in Al-Madinah Almonawra in KSA held during the period from March 2014-March 2015.

Aim of the study: This study aimed at analyzing the effect of population dynamics on the current situation of cutaneous leishmaniasis in Al-Madinah Almonawarah area, a holy city that attracts millions of muslims annually.

Methodology: Epidemiological and clinical data were collected by especial questionnaire and laboratory specimens were collected using skin scraping and needle aspiration. Staining and direct microscopy were done. LST was conducted. Analysis was done using SPSS program.

Results: The study included 164 patients, all of them were men. Saudi nationality comprised around $20 \%$ of the study group, the majority were Egyptians, 26.2\%, followed by Pakistani, 21.3\%.

Conclusion: The presence of non-Saudi nationality as foreign workers, immigrants and refugees has worsened the current situation of the disease.

Keywords: Cutaneous leishmaniasis, refugees, immigration, L. tropica, L. major. Sandfly.

DOI: https://dx.doi.org/10.4314/ahs.v19i3.16

Cite as: Abdalla NM, Abdelgani AM, Osman AA, Mohamed MN. Demographical and population dynamics impact on public health of cutaneous Leishmaniasis in Al-Madinah Almonawra, Saudi Arabia. Afri Health Sci. 2019;19(3): 2421-2430. bttps:// dx.doi. org/10.4314/ahs.v19i3.16
\end{abstract}

\section{Introduction}

Leishmania is a flagellate parasite that causes a wide range of clinical diseases. The parasite is an intracellular pathogen with two forms of life cycles, one inside the vector (Female sandfly) of variable species depending on geo-
Corresponding author:
Nazar M Abdalla,
Department of Microbiology,
College of Medicine,
King Khalid University, Abha,
P.O. 641 zip 61421, Saudi Arabia.
Tel: 009662417525
Fax: 0096672247800
Email: uofgnazar@gmail.com

graphical distribution and the other life cycle inside the host (human and animals). Some form of leishmaniasis need a reservoir mostly an animal. The pathogenic complexes to man include: L. major: mainly causes Zoonotic Cutaneous Leishmaniasis ( ZCL) and Mucocutaneous Leishmaniasis ( MCL ) of the Old World. L. aethiopica: mainly causes Zoonotic Cutaneous Leishmaniasis ( ZCL) and Diffused Cutaneous Leishmaniasis ( DCL) of the Eastern Africa. L. tropica: mainly causes Cutaneous Leishmaniasis (ACL) of the Old World. L. Donovani: mainly causes Visceral Leishmaniasis (VL), Mucocutaneous Cutaneous Leishmaniasis (MCL) and Post Kala-azar Dermal Leishmaniasis (PKDL. Leishmaniasis is prevalent on four continents and is considered endemic in 88 countries, mainly in developing countries. The worldwide prevalence of the disease

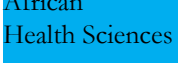

2421
(C) 2019 Abdalla et al. Licensee African Health Sciences. This is an Open Access article distributed under the terms of the Creative commons Attribution License (https://creativecommons.org/licenses/BY/4.0), which permits unrestricted use, distribution, and reproduction in any medium, provided the original work is properly cited. 
is estimated at 12 million cases, with 500,000 new cases per year for visceral forms and of 1-1.5 million for the cutaneous forms. Over $90 \%$ of cases occur in the region Middle East and North Africa Afghanistan, Algeria, Iran, Iraq, Saudi Arabia, Syria, Ethiopia and Sudan ) ${ }^{1}$.

Leishmaniasis is a travelling disease and one of the major diseases associated with people travelling and migration mainly as refugees. This is due to the presence of disease triangle (host, parasite and suitable environment). Sometimes the disease recurs after long dissertation of certain previously known endemic area. This can be explained by the continuos lifecycle of the parasite between the sandfly and the local available animals. A study conducted by Abdalla et al., 2010 in The Green Valley Village, Nuba Mountain in Sudan, which was known to be a highly endemic focus of leishmania that led the villagers to desert it for more than 20 years and the area was known to them as Marad Alsayeed as local terminology. The study revealed the recurrence of the disease among the returned villagers ${ }^{2}$.

The ulcers caused by parasites of the subgenus L. ethiopeca (Ethiopea), L. infantum (Tunisia) L. major (Saudi Arabia and Sudan) are less severe and likely to cure spontaneously or after treatment ${ }^{3}$.

In a recent retrospective study of cutaneous leishmaniasis cases from 1965 to 2002, there were 1,862 patients with cutaneous leishmaniasis in Saudi Aramco health care centre. The disease is more prevalent in the Al-Hasa Oasis (Eastern of Saudi Arabia) and affects males and female equally. Cutaneous leishmaniasis follows a seasonal distribution in parallel with the known activity of the sandfly. The majority $(76 \%)$ of cases occurred in patient $<15$ years of age and the disease affected the extremities more frequently than face. Seventy-one percent of patients presented with a single lesion and $27 \%$ presented with two lesions. Ulcerative cutaneous leishmaniasis was the predominant morphology $(89 \%)$.

The seasonal distribution of reported cases increased in September, remained high in the following months, and reached its peak in January and February. The number of patients began to decline in March and reached its lowest number between April and July.

Simple cutaneous Leishmaniasis (oriental sore ), is a skin involvement of Leishmania parasite in which the amastig-

African Health Sciences Vol 19 Issue 3, September, 2019 ote multiplication is restricted to skin macrophages. The disease is caused by species Leishmania tropica complex in the Old World. The disease starts as a red papule at the site of sandfly inoculation of promastigotes, this eventually ulcerates, become crusted and then heals leaving a depressed scar. Incubation period ranges from 2 weeks to several months. Spontaneous healing of lesions usually occurs within 2 months to a year. Lesions of Cutaneous Leishmaniasis are nodular, nodulo-ulcerative or diffuse . Heavy lymphocytic infiltrate, giant cells and rare epithelial and histolytic elements characterize these lesions. Leishmaniasis recidiva and Diffuse Cutaneous Leishmaniasis (DCL) are non self-healing chronic forms of the disease. The geographic distribution of cutaneous leishmaniasis is mainly determined by the sandfly vectors (Phlebotomus spp.) in Saudi Arabia ${ }^{4}$. However, L. donovani was isolated from a cutaneous lesion in a tourist from Southern France who visited Yemen for two weeks ${ }^{5}$. Similarly documented in Nuba Mountain study ${ }^{6}$. The predominance of $L$. tropica as a causative agent of CL has been reported from Saudi Arabia.

Leishmania tropica is commonly stated to be anthroponotic, although zoonotic transmission has been reported from Saudi Arabia?.

This study was conducted in Al Madinah Almonowra, to determine the impact of migration as a lot of foreign labors and visitors (mainly non-Saudi) are immigrant workers who legally or illegally arrive in this city. Not only does religion and work attract people to this area, but also the instability, due to wars in countries surrounding Saudi Arabia, or other Muslim countries lead to large numbers of people fleeing to Saudi Arabia. Therefore, refugees around the region and mass migration in the North Africa and Middle East could have a huge impact on leishmaniasis particularly in Al Madinah, a holy city that attracts millions of muslims annually. The countries in which these migrants come from, are known to be leishmaniasis endemic countries, so the disease is a trans-frontier health problem.

Vectors in Al-Madinah Almonowra; Sandflies (Diptera: Psychodidea: Pblebotominae) are of considerable obligate vectors of Leishmaniasis.

In a recent study done by Aymen El-Badry et al the entomological survey was carried out in four provinces representing the surrounding of Al-Madinah Almonawra. 


\section{Western Saudi Arabia from May 2007 to April 2008.}

In Al-Madinah Almonawarah, a total of 809 sand flies were collected $72.6 \%$ females and $27.3 \%$ males, they composed of four species of two genera Pblebotomus and Sergentomyia comprising 658 (81.3\%) P. Papatasi, 27 (3.3\%) p. sergenti $34(4.2 \%)$ S. cyldei and $90(11.1 \%)$ S. antennata. P. papatasi was most abundant species of collected sand flies ${ }^{8}$.

Five species of rodents were caught, namely, Meriories libycus; Psammomys obesus; Rattus rattus; Jaculus jaculus and Hystrix indica, with the former as the most dominant (90\%). Examination of these rodents revealed detectable leishmanial parasite in Almadinah Almonawra and Tabouk regions all proved to be Leishmania major Zymodeme LON -4. The most prominent research was the National Leishmaniasis Research Project (NLRP) held at Al-Hassa Oasis in the Eastern Region of the Kingdom in which the analysis of isoenzyme data was used. During this project, the species of Leishmania parasite responsible for Zoonotic Cutaneous leishmaniasis (ZCL) in this region was determined to be Leishmania major Zymodeme LON-4. The potential vectors of this Zymodeme and the main reservoir animal hosts were also identified to be Pblebotomus papata$s i^{9}$ and the fat sand mouse, Psammomys obesus Cretzschmar,1828 was the reservoir host ${ }^{10}$.

In the South-Western parts (Aseer, Jazan and Al-Baha regions) of the Kingdom during the same period. The parasite responsible for ZCL in Tehama lowlands of these areas were also found to be related to L. major Zymodeme LON-4, whereas at high lands of Sarawat Mountains in Asir and Al-Baha regions L. tropica is the main cause of Cutaneous leishmaniasis.

Several Zymodeme of this species were identified; Zymodeme LON-10, LON-63, LON-71, LON-72 and LON73 and their potential vector was recognized as phlebotomus sergenti ${ }^{11}$. In the Central parts of the Kingdom (Riyadh and Al-Kharj areas) further studies conducted proved that L. major Zymodeme LON-4 is the major cause of ZCL and the main reservoir host was determined to be the Libyean rodent, Merionies libycus Lichtenstein, 1823, and they determined the potential vector in these areas to be Pblebotomus papatasi ${ }^{12}$.

In a study, done by (Dajem and Abdalla et al 2010 unpublished paper) the L. major aymodeme LON-4 was isolated also from the Libyan rodent M. Lybicus (Muridae family). It is cosmopolitan species of rodent. It is found in Afghanistan, Algeria, China, Egypt, Iran, Iraq, Jordan,Kazakhstan, Libya, Mauritania, Morocco, Saudi Arabia, Syria, Tunisia, Turkmenistan, Uzbekistan, and Western Sahara.

Iso-enzyme characterization of Leishmania isolates from Almadinah Almonawarah show that all isolates of Leishmania parasite from human patients or from infected rodents characterized by the iso-enzyme electrophoresis were found belong to the Leishmania major Zymodeme LON-4. Isoenzyme electrophoresis profiles for two enzymes, MDH and ASAT tested in form humans and Lybean jird respectively.

Classification of the isolates drawn from the ulcers taken from patients reveals that the causative agent was L.major Zymodeme LON-4. L. major parasite was also detected in Libyan rodents prevalent in the areas studied. The distinctive isoenzyme profile of $L$. major isolated from humans patients and rodents host in these areas were both identified to be Zymodeme LON- 4.

\section{Theory and calculation}

Almadinah Almonawarah is a holy city; many people from various parts of the world visit it all year round. This population dynamics will be a great role in transmission of cutaneous leishmaniasis. This study will evaluate this effect and the burden on public health.

\section{Methodology \\ Study area}

This study was conducted in Almadinah Almonawarah Western region of Saudi Arabia, its elevation above sea level is 630 meters, the average annual temperature maximum, $30^{\circ} \mathrm{C}$ to minimum $20^{\circ} \mathrm{C}$, with average humidity $33 \%$, and the average annual rainfall of 38.4 millimeter, most cases of this study were staying in two districts and Al-Madinah city. Al-Yutamah around seventy five kilometer North to Al-Madinah and Shajow located hundred kilometers South to Al-Madinah. It is a semi-cultivated desert area with houses and many farms containing sheep and poultry breeding houses, irrigated by underground water, which has created a rich habitat supporting endemic animal including desert rodents and sand flies populations. Both areas have a unique nature and this is reflected by the presence of the; various type of soil ( sand, mud and rocky soil ), variable weather and climatic condition such as heavy rain, hot summer and cold dry winter. Av- 
erage temperature is high during summer (August mean temperature: $39^{\circ} \mathrm{C}$ ), while in winter it is generally cooler (January mean temperature: $25^{\circ} \mathrm{C}$ ) and the presence of different types of plants in many farms, this facilitated the distribution of insect vectors and animal reservoirs in the area.

\section{Study population}

The population of the Utamah district is around 4 thousand persons, and in this town, there is Administrative Public Council, Police Station, primary, secondary and higher schools, one Primary Health Care Center and Ambulance Center.

Many villages surrounding Utamah town, where cutaneous leishmaniasis is endemic, especially Negeah village about seven kilometers South to Utamah, were most cases of the study were selected. All the village people are relatives with non-indigenous workers, their main income depends on agriculture and live stock, i.e., working as farmers and shepherds.

Most of the foreign inhabitants live in sub-standard housing conditions, having domestic animals in their houses: sheep, cows, goats and dogs.

The population of the Shajow district is around 350,000 persons, and in this town, there is Police Station, primary, secondary and higher schools, one Primary Health Care Center.

The third area was Almadinah Almonawarah city, which is well developed city with all facilities, and has many palm trees, most cases who participated in this study were from the farm in Khulial street in the south of the city, the population of the city around 3.5 million.

All patients with CL attending Utamah, Shajow health centre and Al-migat Hospitals during the study period from March 2010 to September 2011 were included in the study (total number 164 patients).

\section{Demographic, epidemiological and clinical data}

Clinical, epidemiological and demographic data were collected using a special questionnaire. All cases of cutaneous leishmaniasis were clinically and laboratory diagnosed mainly microscopically confirmed.

\section{Clinical diagnosis}

All patients were diagnosed clinically by inspection of the ulcers. The ulcers were very characteristic with prominent edges, volcanic appearance, started with papules and took long term mostly one to six months without pain.

\section{Parasitological diagnosis}

For all patients $(n=164)$ samples from the edges of the lesion were collected using an insulin injection, and aspiration was done and put in two clean microscopic slides with drops of normal saline, then the slides were left to dry completely.

For Giemsa stain, the slides were fixed with 100\% methanol, left to dry then covered with 10\% Giemsa stain and left for 15 minutes then rinsed with distilled water by pouring water on the edge of the slide.

The smear were allowed to dry and then examined carefully for Leishmania amastigote microscopically at X100 power using the immersion oil lens. No culture was made for any sample in this study. In some cases using the Leishman stain by covering the slides with stain for 30 mints then left to air dried, finely exam microscopically at X100 power using immersion oil lens.

All these techniques were performed in the laboratory of Al-miquat Hospital in Al-Madinah Almonawarah

\section{Ethical considerations}

All patients with active lesions who took part in this research project had given informed consent. All the risks had been explained to them by the principal investigator before the beginning of the programme. Participants could choose to withdraw from the study at any time if they wished. This study was conducted after permission of the health authority of the vector born diseases in Al-Madinah region. The procedures followed in this study were in accordance with the ethical standards of the responsible committee on human experimentation (King Khalid University, Saudi Arabia) and in keeping with the Helsinki Declaration of 1964, as revised in 1975, 1983, 1989, 1996, and 2000. Human rights were fully observed.

\section{Data analysis techniques}

The collected data were statistically analyzed using the SPSS version 19.

\section{Results}

\section{Epidemiological and demographic analysis}

This study includes 164 patients. All of them were male, because of cultural and religious reasons. Age distribution of study group ranged from 0 to more than 30 years old. Those from 0 to less than 10 years were 12 patients (7.4) patients their age from 10 to 20 years were 13 (8\%). Patients whose age ranged from 21 to 30years were 78 (47.9) those more than 31 years of age were 61 (36.8\%). 
The mean age was 29.2.+ 2.5. Most of the patients under study were single $(89 \%)$. The study group was from different nationality; their distribution is shown in table 1. Concerning patient occupation; farmers were the majority $(48.8 \%$ ), followed by builders $(20.1 \%)$, students were $7.3 \%$, while the least group was poultry farmers (4,
$2.4 \%$ ). Regarding sleeping habits of the participants most of them sleep indoor $(94,58 \%)$ and this mostly depended on the availability of the electricity. Other important factors were usage of the bed nets. Those who never used it were $85.4 \%$ table 2 . Moreover most of the patients $(83 \%)$ were not using protective cloths.

Clinical presentation of the study group

Table 1. Nationality of the study group

\begin{tabular}{|l|l|l|}
\hline Country & Number of patients & Percent \% \\
\hline Egypt & 43 & 26.2 \\
\hline Sudan & 17 & 10.4 \\
\hline Bangladesh & 12 & 7.3 \\
\hline Pakistan & 35 & 21.3 \\
\hline India & 17 & 10.3 \\
\hline Saudi Arabia & 32 & 19.5 \\
\hline Yemen & 8 & 4.9 \\
\hline Total & 164 & 100 \\
\hline
\end{tabular}

Table 2. Usage of impregnated bed nets among study group

\begin{tabular}{|l|l|l|}
\hline Usage of bed nets & Number of patients & Percent \% \\
\hline Rarely used & 2 & 1.2 \\
\hline Always used & 22 & 13.4 \\
\hline Never used & 140 & 85.4 \\
\hline Total & 164 & 100 \\
\hline
\end{tabular}

Concerning the sites of the lesions, most occurred in only in the upper extremities $41.5 \%$, as compared to other sites shown in fig 1 . Those that had lesions in their face were children under the age of 7 years .

Most of the patients had a low number of lesions; $1-3$ $(78 \%)$ and 4 , and more lesions found in $22 \%$ of patients. For clinical confirmation, most of the patients ( $86.6 \%$ ) had visited one of the medical services (health center or hospital) within 1-3 months from the onset of the symptoms and those went within 4-6 months were $11 \%$, while only one patient attended the health center more than six months after the appearance of the lesion. Almost all patients received medication $(91.5 \%)$.

\section{Laboratory results}

Concerning the results of the microscopic examination, 88 patients were positive. In 76 patients receiving treatment depending on clinical diagnose, all of them received it from health center of Yutamah and Shajow villages, as they had no facilities of laboratory investigation. The results of leishmanin skin test (LST) (montonegro test) were negative in all patients.

Comparison between the nutritional statuses of patient and the severity of the disease, was expressed as number of ulcers. Among 71 patients out of the total 164 patients, those were underweight, had normal weight, or were overweight with the number of lesion, the results shown in table 3 . 
Table 3. Comparison between nutritional status and severity of the disease in 71 patents

\begin{tabular}{|c|c|c|c|}
\hline \multirow{2}{*}{$\begin{array}{l}\text { Body mass index } \\
\text { (Nutritional status) }\end{array}$} & \multicolumn{2}{|c|}{ Clinical presentation } & \multirow[b]{2}{*}{$>6$ lesion } \\
\hline & 1-3 lesions & 4-6 lesions & \\
\hline $\begin{array}{l}\text { Under wt. } \\
\text { BMI }<19\end{array}$ & 16 & 8 & 2 \\
\hline $\begin{array}{l}\text { Normal Wt. } \\
\text { BMI } 20-<25\end{array}$ & 20 & 12 & 4 \\
\hline Over wt. BMI > 25 & 6 & 2 & 1 \\
\hline
\end{tabular}

\section{Discussion}

Cutaneous leishmaniasis (CL) is a vector-mediated skin disease, characterized by chronic wounds on the skin and caused by macrophages in protozoan parasites. Foreign workers are affected significantly in leishmaniasis, due to the fact that most of them came from leishmania endemic countries such as, Turkey, Syria, Tunisia, Sudan, Egypt, Ethiopia, Yemen and others. Usually the standard of living when they resettle in Saudi Arabia is low, and thus leads to low nutritional status, which left them vulnerable to leishmaniasis.

The Syrian refugee crisishas precipitated a catastrophic outbreak of Old World cutaneous leishmaniasis now affecting hundreds of thousands of people living in refugee camps or trapped in conflict zones. A similar situation may also be unfolding in Eastern Libya and Yemen ${ }^{13-18}$.

cutaneous leishmaniasis prevalence in Syria was restricted to 2 areas to which it is endemic (Aleppo and Damascus); According to the Lebanese Ministry of Health, during 2000-2012, only 6 cutaneous leishmaniasis cases were reported in Lebanon. However in 2013 alone, 1,033 new cases were reported, of which $96.6 \%$ occurred among the displaced Syrian refugee populations ${ }^{19-23}$. cutaneous leishmaniasis prevalence in Sudan ${ }^{24}$, The first cases of cutaneous leishmaniasis in Sudan were reported by Thomson and Palfour in 1910, in two Egyptian solders who had contracted the disease in upper Egypt. The first indigenous case was described by Archibald in 1911 in a native form in the Nuba Mountains, Kordofan province in Western Sudan . Sporadic cases were reported by Christopherson in 1914 in Khartoum and by Kirk\&Drow in1938 in Blue Nile and Darfur province. A single case was described by Kirk in Equatoria province in 1942.

There have been several reported outbreaks of the disease in Sudan, the last being in Khartoum State in 1985 and involving at least 10,000 cases. Following the original epidemic, a study has shown that about $30 \%$ of the examined individuals from Tuti Island had sub-clinical infections as proven by a positive leishmanin skin test in the absence of scars or previous history of active skin lesion. By contrast, during the epidemic of the 1980 s, $80 \%$ of patients from Tuti Island and other parts of Khartoum were active parasitologically confirmed cases. A study on leishmania reservoir conducted in The Green Valley Village in Nuba Mountain West of Sudan, using direct microscopy and modified direct agglutination test (DAT-R), ELISA, K39 and PCR.

Cutaneous leishmaniasis (CL) is a major public health concern in Turkey and Sanliurfa represents the most endemic city in Turkey. Although children are most commonly affected by CL, detailed studies of pediatric CL in Turkey are lacking. An increase in pediatric CL patients within the last four years. Analysis of pediatric CL patients by age revealed significant differences in CL progression. The data suggests that children between $0-5$ years old responded better than other groups to intra-lesional treatment, since they received more often a single cycle of Intralesional treatment, although follow up observation is required since they were more prone to develop recidivans. Eleven-15 year old patients comprised the largest percentage of patients receiving two or three cycles of intralesional treatment, suggesting that this group did not respond efficiently to intralesional treatment and highlighting the need for more effective therapeutic strategies against CL. Turkey is an endemic country for CL and the main causative agent is L. tropica. However, CL caused by L. infantum and L. major has also been reported especially from Eastern part of the Mediterranean Region ${ }^{25-28}$. Cutaneous leishmaniasis (CL) is endemic in the highlands of Ethiopia, and almost always caused by Leishmania aethiopica. Hitherto, Addis Ababa (the capital city of Ethio- 
pia) was not considered endemic for CL, mainly due to absence of epidemiological and field ecological studies. This report summarizes the preliminary epidemiological investigation that proved the existence of active transmission in SouthEastern Addis Ababa and existence of isolated zoonotic foci of CL in South Eastern Addis Ababa, with $P$. longipes as the likely vector and $H$. brucei as the natural reservoir host $\mathrm{t}^{29,30}$.

Species-specific diagnosis was performed in 66 patients with cutaneous leishmaniasis (CL) living in Tataouine focus in SouthEastern Tunisia. Leishmania DNA was extracted directly from dermal scrapings and from parasites obtained in culture. Species were identified by using polymerase chain reaction-restriction fragment length polymorphism analysis for internal transcribed spacer region 1 and isoenzyme analysis. Leishmania tropica and L. major were identified in $31(47 \%)$ and $35(53 \%)$ cases respectively. Leishmania tropica CL cases were geographically scattered, and L. major CL cases were clustered. Lesions caused by L. tropica were mostly single (83.8\%) and face-localized (55.8\%), and lesions caused by L. major were multiple $(57.1 \%$; $\mathrm{P}<0.001)$ and situated on limbs (83.7\%; P < 0.001). For both species, most lesion onsets were reported during June-January. However, lesions that emerged during February-May were mainly caused by L. tropica $(83.3 \%$; $\mathrm{P}<0.01)$. Moreover, the delay before seeking medical advice was higher for $L$. tropica infections than for L. major infections $(\mathrm{P}<0.05)^{31-34}$.

Cutaneous leishmaniasis is an endemic disease in the Southern and Southeastern Anatolia region and is still an important public health problem in Turkey ${ }^{35}$. Because of the civil war in Syria, immigrants to this region in the last 3 years have begun to more frequently present with this disease. The aim of this study was to draw attention to the dramatic increase in new cases with CL after the beginning of the civil war in Syria. Immigrations to endemic regions of Turkey from neighbouring countries where CL incidence is higher may lead to large increases in case numbers. In order to decrease the risk of exposure, housing conditions of the refugees must be improved, routine health controls must be performed, effective measures must be set in place for vector control, and infected individuals must be diagnosed and treated to prevent spread of the infection.
As cutaneous leishmaniasis prevalence is high in other middle East countries including $\operatorname{Iraq}^{36}$, Jordan ${ }^{37}$, $\operatorname{Iran}^{38}$ and Afghanistan ${ }^{39}$, it might increase the local prevalence in Saudi Arabia, due to immigrations and refugees from citizens of these unstable countries.

This is a field base cross-sectional study conducted in Al-Madinah Almonawarah in KSA in order to study the effect of population dynamics in form of migration, refugees and foreign labors on real situation of cutaneous leishmaniasis in the holy city of Al-Madinah Almonawarah. All patientS included in this study were male due to culture and religious reasons, total number was 164 . The incidence rate of CL infection was $85.4 \%$ in patients over 15 years old. This finding is lower than that reported for but higher than in $\operatorname{Iran}(38 \%)$ and Turkey $(45 \%)^{40}$. It is postulated that the decrease in incidence with age was due to development of immunity by previous infections. This study indicates that the incidence rate of multiple lesions in CL patients is 58\%. This result could be due to long periods of exposure to Plebotomine sand flies and the high population density of sand flies in this area.

Regarding the distribution of CL lesions in this study, we found that the higher proportion of the lesions were located solely on the upper limbs (41.5\%), and lower limbs $(17 \%)$. These observations are consistent with studies concerning Turkey and Iran.

Half of the occupation in this study were farming (80, $48.8 \%$ ). This will lead to outdoors transmission. Most patients in this study were not using the bednets (140, $85.4 \%$ ) neither using any protective clothes or methods, this led to increase transmission of the disease. The importance of using bednets and protective cloth have been demonstrated by many studies in Gadareff state Eastern Sudan and White Nile state in Sudan .

A multifaceted, collaborative approach must be taken to control the incidence of $\mathrm{CL}^{41}$, with priority given to initiatives that will not only aid in the prevention and control of CL but also improve the living conditions and survival of refugee populations. The World Health Assembly already adopted a resolution in 2007 to address the global burden of leishmaniasis ${ }^{42}$, but immediate action must be taken to address the spreading burden of CL in the Middle East. By no fault of their own, refugees and displaced individuals are often fleeing from one unimaginable circumstance of horror and violence to another of poverty and disease ${ }^{43}$. International communities have a responsi- 
bility to pay greater attention to this pressing issue, and it is imperative that proactive measures are taken to establish efficient and sustainable initiatives aimed at diagnosing, treating, and preventing CL as the conflicts in Syria, Iraq, Libya, and Yemen continue.

\section{Conclusion}

This study indicates that CL is endemic in Al-Madinah Almonawra region. Non-Saudi settlers, immigrants, foreign workers and refugees are the predominant patients. Case detection and treatment as well as control of the vector and reservoir will yield to eliminate this disease.

\section{Conflict of interest}

There is no conflict of interest for this article.

\section{Acknowledgments}

We would like to thanks the vector control unit at Al--Madinah Almonawarah Health Affair for their sincere collaboration. Our gratitude to the doctors and health personnel of the health centers (Yutamah and Shajow) and Al-Mequat Hospital.

\section{References}

1. Report of WHO Expert committee in control of Leishmaniasis. WHO technical report series. 2010. http:/ /apps.who.int/iris/bitstream/10665/44412/1/ who_trs_949_eng.pdf

2. Abdalla NM . Comparative study of immune-diagnostic tools with polymerase chain reaction in sub-clinical leishmaniasis isolates. 2011; 12:34-39.doi: http://dx. doi.org/10.3329/jom.v12i1.5422

3. Pirmez C Pirmez V, Silva Trajanod A, Paes-Oliveira Neto M, DA-Cruz, Goncalves-DA-Costa, M Catanho W Degrave, Fernandes O. Use of pcr in diagnosis of human american tegumentary leishmanias is in Rio De janeiro, Brazil. Journal of Clinical Microbiology. 1999:37,18191823.doi:10.1128/ jcm.40.2.601-606. 2002

4. Magill AJ, Grogl M, Johnson SC, Gasser RA, JR. Visceral infection due to leishmania tropica in a veteran of operation desert storm who presented 2 years after leaving saudi arabia. Clin. Infect. Dis. 1994: 19: 805-806. doi: 10.4269/ajtmh.2012.11-0749

5. Khatri ML, Haider N., Cutaneous leishmaniasis in yemen. int j dermatol. 1999 aug;38(8):587-90. https://www. ncbi.nlm.nih.gov/pubmed/10487447.

6. Abdalla NM. Evaluation of gene targeted PCR and molecular hybridization used in diagnosis of human leishmania isolates. J. of Biotechnology. 2010.: 9 (2): 212-217. DOI: 10.3923/biotech.2010.212.217 .

7. AL-Zahrani MA, Peters W, Evans DA, Chin C, Smith V, Lane RP. Phlebotomus sergenti, a vector of leishmania tropica in saudi arabia. Transr Soc Trop Med Hyg. 1988; 82:416. doi: $10.1371 /$ journal.pntd.0003687

8. Widaa SO, Ahmed KA, Bari AA, Ali MM, Ibrahim M. A, Bashir M. A, Mastour A. A, Zakkia Z. A, Hassan M. M, Sandflies (Diptera: Psychodidae) in a focus of visceral leishmaniasis in White Nile, Sudan. Mem Inst Oswaldo Cruz. Riode De Janerio, 107 (4) June 2012: 70-475 DOI: 10.1590/ S0074-02762012000400005.

9. El-Badry A, Al-Juhani A, Ibrahim El-, Al-Zubiany $\mathrm{S}$. Distribution of sand flies in El-Nekheil province, in Al-Madinah Al-Munawwarah region, western of Saudi Arabia. Parasitol Res. 2008 Jun;103(1):151-6. doi: 10.1007/ s00436-008-0942-3.

10. Hussein HS, Kasim AA, Shawa YR. The prevalence and pathology of eimeria infections in camels in saudi arabia. Journal of Comparative Pathology. 1987 may 31;97(3):293-7. DOI: 10.1016/0021-9975(87)90093-4.

11. AL-Zahrani MA, Peters W, Evans DA, Smith V, Ching CI. Leishmania infecting man and wild animals in saudi arabia. 6. Cutaneous leishmania of man in the southwest. Trans r Soc Trop Med Hyg. 1989; 83:621-628. https:/ / www.ncbi.nlm.nih.gov/pubmed/2617600

12. Ibrahim EA, Mustafa MB, AL Amri SA, ALSeghayer SM, Hussein SM, Gradoni L. Meriones Libycus (Rodentia: Gerbillidae), A possible reservoir host of zoonotic Cutaneous Leishmaniasis in Riyadh province, Saudi Arabia. Transactions of the Royal Society of Tropical Medicine and Hygiene. 1994 jan 1;88(1):39. Http://www.sciencedirect. com/science/journal/00359203/88/1

13. Hayani K, Dandashli A, Weisshaar E. Cutaneous leishmaniasis in syria: clinical features, current status and the effects of war. acta derm venereol. 2015;95:62-6. http:/ / dx.doi.org/10.2340/ 00015555-1988

14. Kallel K, Haouas N, Pratlong F, Kaouech E, Belhadj S, Anane S, ET AL. Cutaneous leishmaniasis caused by leishmania infantum mon-24 in tunisia: extension of the focus to the center of the country. Bullsoc Pathol Exot. 1990. 2008; 101(1):29-31. http://dx.doi.org/10.1371/ journal.pntd.0004545

15. Abdalla NM, Abdelgani AM, Osman AA, Sarhan MA. Case Report: utaneous leishmaniasis in EL-Madinna manowra region, Saudi Arabia. Bangladesh J. of Med- 
ical Science. july 2013 (vol. 12, no. 3) 325-330. issn 22234721 (print) 2076-0299. (Electronic) DOI: http:/ /dx.doi. org/10.3329/bjms.v12i3.13189 .

16. Aoun K, Bouratbine A. Cutaneous leishmaniasis in North Africa: a review. Parasite. 2014 MAR 14; 21 (14). DOI: $10.1051 /$ parasite/2014014

17. Pratlong F, Dereure J, Ravel C, Lami P, Balard Y, Serres G, et aL. geographical distribution and epidemiological features of old world cutaneous leishmaniasis foci, based on the isoenzyme analysis of 1048 strains. Trop Med Int. 2009 sep; 14(9):10711085. doi: 10.1111/j.13653156.2009.02336.x

18. Hotez P, Savioli L, Fenwick A. Neglected tropical diseases of the Middle East and North Africa: Review of their prevalence, distribution, and opportunities for control. PloS Negl Trop Dis. 2012 FEB 28; 8. TDR. D. http:// dx.doi.org/10.1371/journal.pntd.0001475

19. Waleed S. AL-Salem 1, David M,. Pigot T, Ikrishanth I, Subramaniam,1, lee Rafuse Haines, Louise Kelly-Hope, David H. Molyneux, Simon I. Hay, Aalvaro AcostaSerrano. Cutaneous leishmaniasis and conflict in syria. Emerging Infectious Diseases. www.cdc.gov/eid • vol. 22, no. 5, May 2016. 931-33. doi: 10.3201/eid2205.160042

20. Bin DS, Mostafa OM, Abdoon A, AL-Quraishy SA, Algahtani AA. Isoenzyme electrophetic characterization of leishmania major, the causative agent of zoonotic cutaneous leishmaniasis in north and west saudi arabia. Journal of the Egyptian Society of Parasitology, 2010; 40(2):465-78. https://www.ncbi.nlm.nih.gov/pubmed/21246954

21. Haddad N, Saliba H, Altawil A, Villinsky J, AL-Nahhas S. Cutaneous leishmaniasis in the central provinces of hama and edlib in syria: vector identification and parasite typing. Parasit Vectors. 2015;8:524. http://dx.doi. org/10.1186/s13071-015-1147-0

22. ALAwieh A, Musharrafieh U, Jaber A, Berry A, Ghosn N, Bizri AR. Revisiting leishmaniasis in the time of war: the syrian conflict and the lebanese outbreak. Int J Infect Dis. 2014;29:115-9. http://dx.doi.org/10.1016/j. ijid.2014.04.023

23. Koltas IS, Eroglu F, Alabaz D, Uzun S. The emergence of leishmania major and leishmania donovani in southern turkey. Transr Soc Trop Med Hyg. 2014;108:154 8. http://dx.doi.org/ 10.1093/trstmh/tRT119

24. Elnaiem DA, Conners S, Thmoson M, Hassan MM, Hassan KH, Aboud MA, Ashford RW. Environmental determinants of the distribution of phlebotomus orientalis in sudan. Ann Trop Med Parasitol. 1998; 92: 877-887. https://www.ncbi.nlm.nih.gov/pubmed/10396348

25. SvobodovÁ M, Alten B, Zídková L, Dvořák V. Cutaneous leishmaniasis caused by leishmania infantum transmitted by phlebotomus tobbi. Int J. 2009; available: http://www.sciencedirect.com/science/article/ pii/ s0020751908002701

26. Koltas I, Eroglu F, Alabaz D. The emergence of leishmania major and leishmania donovani in southern turkey. Trans. 2014; available: http://trstmh.oxfordjournals.org/ content/early/2014/01/20/trstmh. trt119.short

27. Du R, Hotez pJ, AL-Salem WS, Acosta-Serrano A, Ashford R, Rioux J-A, et al. Old world cutaneous leishmaniasis and refugee crises in the middle east and north africa. rafati s, editor. PloS Negl Trop Dis. Public Library of Science; 2016; 10: e0004545. doi: 10.1371/journal. pntd.0004545 pmid: 27227772

28. Mustafa Aksoy, Nebiye doni, Hatice Uce Ozkul, Yavuz Yesilova, Nurittin Ardic, Abdullah Yesilova, Jennifer Ahn-Jarvis , Steve Oghumu , Cesar Terrazas, Abhayr Satoskar. pediatric cutaneous leishmaniasis in an endemic region in turkey: a retrospective analysis of 8786 cases during 1998-2014. PloS Neglected Tropical Diseases. doi:10.1371/journal.pntd.0004835 july 14, 2016.

29. Wossenseged Lemma, Girume Erenso, Endalamaw Gadisa, Meshesha Balkew, Teshome Gebre-Michael and Asrat Hailu. A Zoonotic focus of cutaneous leishmaniasis in addis ababa, ethiopia. Parasites \& Vectors. 2009, 2:60 doi:10.1186/1756-3305-2-60

30. Hailu A, Gebre-Michael T, Berhe N, Balkew M: Leishmaniasis in ethiopia. in epidemiology and ecology of health and disease in ethiopia 1st edition. edited by: berhane y, hailemariam d, kloos h. Addis Ababa: Shama Press; 2006:615-634. doi:10.1186/1756-3305-2-60

31. Bousslimi N, Aoun K, Ben-Abdai, Ben-ALayaBouafif N, Raouane M, Bouratbine A. Epidemiologic and clinical features of cutaneous leishmaniasis in southeastern tunisia. Am J Trop Med Hyg. 2010 nov;83(5):10349. doi: 10.4269/ajtmh.2010.10-0234.

32. Rioux jA, Lanotte G, Pratlong F. IN: LEISHMANIA: Taxonomie Et Phylogenèse; Applications éco-épidémiologiques. Rioux ja, editor. montpellier, France: Imeee; 1986. pp. 139-142. http://dx.doi.org/10.1371/journal. pntd.0004204

33. Pratlong F, Dereure J, Ravel C, Balard Y, Serres G, Lanotte $G$, Rioux JA. Geographical distribution and epidemiological features of old world cutaneous leishmaniasis foci, based on the isoenzyme analysis of 1,048 strains. Trop 
Med Int Health. 2009;14:1071-1085. doi: 10.1111/j.13653156.2009.02336.x]

34. Aoun K, Amri F, Chouihi E, Haouas N, Bedoui K, Benikhlef R, Ghrab J, Babba H, Chahed MK, Harrat Z, Bouratbine A. Epidémiologie de leishmania (1.) infantum, 1. major et l. killicki en tunisie: résultats et analyse de l'identification de 226 isolats humains et canins et revue de la littérature. Bull Soc Pathol Exot. 2008;101:323-328. https://www.ncbi.nlm.nih.gov/pubmed/18956815.

35. Inci R, Ozturk P, Mulayim MK, Ozyurt K, Alatas ET, Inci MF. Effect of the syrian civil war on prevalence of Cutaneous Leishmaniasis in SouthEastern Anatolia, Turkey. Med Sci Monit. 2015 jul 20;21:2100-4. doi: 10.12659/ MSM.893977.

36. WHO, Communicable disease working group on emergencies, HQ division of communicable disease control, emro, who office, baghdad. WHO office, baghdad. communicable disease toolkit, iraq crisis. WHO, 2003:3944. http://www.who.int/diseasecontrol_emergencies/ toolkits/iraq_profile_ok.pdf

37. Saliba EK, Saleh N, Oumeish OY, Khoury S, Bisharat Z, et al.. The endemicity of Leishmania tropica (zymodeme mon-137) in the eira-yarqa area of salt district, jordan. Ann Trop Med Parasitol. 1997; 91: 453-459. doi: 10.3201/eid0604.000405.

38. Akhoundi M, Hajjaran H, Baghaei A, Mohebali M.
Geographical Distribution of Leishmania Species of Human Cutaneous Leishmaniasis in Fars Province, Southern Iran. Iran J Parasitol. 2013 Jan-Mar; 8(1): 85-91. https:/ / www.ncbi.nlm.nih.gov/pmc/articles/PMC3655245/ PMCID: PMC3655245

39. Faulde MK, Heyl G, Amirih ML, Zoonotic Cutaneous Leishmaniasis, Afghanistan. Emerg Infect Dis. 2006 Oct; 12(10): 1623-1624. doi: 10.3201/eid1210.060076.

PMCID: PMC3290938

40. WHO, 2007 (World Health Organization), available from:<http://www.who.int/tdr/diseases/leish/diseaseinfo.htm $>$.

41. Yaghoobi-Ershadi MR, Hanafi-Bojd AA, Javadian E, Jafari R, Zahraei-Ramazani AR, Mohebali M. A new focus of cutaneous leishmaniasis caused by Leishmania tropica. Saudi Med J. 2002; 23(3): 291-4. https://www. ncbi.nlm.nih.gov/pubmed/11938418

42. Postigo J. Leishmaniasis In the World Health Organization, Eastern Mediterranean Region. J Antimicrob Agents. 2010 nov; 36(1):s62-5. doi: 10.1016/j.ijantimicag.2010.06.023.

43. Du I , Peter J. Hote Z, Waleed S. AL-Salem, Alvaro Acosta-Serrano . Old world Cutaneous Leishmaniasis and refugee crises in the Middle East and North Africa rebecca. PloS Neglected Tropical Diseases. doi:10.1371/journal.pntd.0004545 may 26, 2016. 